\title{
Dialogue for Air, Air for Dialogue: Towards Shared Responsibilities in COPD Practice
}

\author{
Merel A. Visse • Truus Teunissen - Albert Peters • \\ Guy A. M. Widdershoven - Tineke A. Abma
}

Published online: 10 January 2010

(C) Springer Science+Business Media, LLC 2009

\begin{abstract}
For the past several years patients have been expected to play a key role in their recovery. Self management and disease management have reached a hype status. Considering these recent trends what does this mean for the division of responsibilities between doctors and patients? What kind of role should healthcare providers play? With findings based on a qualitative research project of an innovative practice for people with Chronic Obstructive Pulmonary Disease (COPD) we reflect on these questions. In-depth interviews conducted with people with COPD, physiotherapists and a pulmonologist show that shifting responsibilities require a supportive attitude from healthcare providers and a dialogical communication between patients and professionals. Our findings show more is needed in order to motivate people with COPD to take responsibility and become co-owners in a process of recovery. The case example illustrates that people with COPD need support from fellow patients to learn to accept their disabilities. Awareness that COPD is more than just a lack of air, that mind and body interact, is a first step to investigate other potential problems and to enhance one's quality of life.
\end{abstract}

Keywords Autonomy - COPD - Self-management · Mind-body · Deliberation · Dialogue $\cdot$ Interdisciplinary $\cdot$ Responsibility

M. A. Visse $(\bowtie)$ - G. A. M. Widdershoven · T. A. Abma

VU University Medical Center, Department of Metamedica/Medical Humanities, Amsterdam, The Netherlands

e-mail: m.visse@vumc.nl

T. Teunissen

Astma Lungpatient Foundation, Leusden, The Netherlands

A. Peters

COPD Centre, Ter Gooi Ziekenhuizen, Blaricum, The Netherlands 


\section{Introduction}

Responsibilities between doctors and patients with a chronic disease have dramatically shifted over the past decades [25, 37]. Examples are everywhere. Consider an advertisement for healthcare professionals containing a photograph of a mentally disabled boy with Down Syndrome, wearing a suit, sitting behind a large desk in an office (Volkskrant, 6/7 December 2008). The boy is dressed as a director, and the advertisement mentions him as 'the employer'. The suggestion is clear: this institution pictures their clients as being in control. Historically we are used to seeing doctors as being in charge of the disease; today many responsibilities are transferred to patients/clients. Patients are no longer passive recipients of care, but are perceived as informed, autonomous experts, directing their life and care. While patients are expected to act as consumers making their own decisions, doctors and other healthcare professionals are expected to operate as providers of objective and scientific information (versus judges of the patients' interests). The shifting of responsibilities are reflected in new organizational arrangements of care. These arrangements, whether called disease management, self-management, integrated care or otherwise, all aim to maximize the autonomy of patients.

The notion of autonomy is widely accepted in our Western culture. It has gained the status of a core principle within the field of bioethics (besides the principles of doing no harm, benefiting and doing justice). In bioethics an autonomous person is defined as someone who is independent of others and free to make his own choices without interference of others [8]. The idea of the patient as consumer is also reflected in healthcare policies and legislation, for instance, in the Dutch Medical Treatment Agreement Act (WGBO). According to this Act healthcare professionals have the duty to inform patients $[17,36]$. The trend towards consumerism is not unique for the Netherlands and can also be seen in other Western countries. In the UK, for example, governmental policy documents spanning the last decade clearly envision the patient as a consumer of healthcare [9, 16, 32, 38].

In the field of medical sociology serious doubts have been raised about the consumerist ethos in healthcare. First of all, patients are not always adequately informed and fully aware of the value or relevance of care as a 'product' $[6,15,32]$. Furthermore, unequal power relations should be taken into account. Patients often find it hard to articulate their needs, and many patients feel that their voice is overridden, silenced, or stripped of personal meaning and social context in medical encounters [7, 9, 13-15, 26, 32]. Healthcare professionals often lack the required communication skills to elicit patients' preferences and involve them in treatment decisions $[15,33]$. Patients may well expect more than just information from their doctor, such as an advice from an expert [20] or support and a listening ear to deliberate their situation with an empathic caregiver [29]. If mutual expectations are not discussed, this may lead to misunderstandings, which ultimately have a negative effect on the quality of care $[4,9,26]$.

The aim of this article is to show that the idea of self-management is indeed much more complicated than just giving information to the patient as consumer. It also entails relational, narrative and communicative work since relationships and responsibilities shift. While most studies either promote or critique the concept of 
self management in chronic care, we aim to examine the possibilities to enrich the notion of self-management in a dialectical circle between practical understandings and theoretical insights from ethics [43]. Using a practical case example, a Dutch centre for people with Chronic Obstructive Pulmonary Disease (COPD), we will investigate the changing division of responsibilities [42]. We will argue that this calls for a dialogical approach to healthcare.

\section{Methodology}

The first two authors of this article were asked to evaluate two programs in which healthcare for chronically ill people is improved by care innovations stemming from dialogical interactions in the triad of patient, nurse and doctor. The evaluation would focus on values such as autonomy, self management, enthusiasm and genuine involvement. The researchers were also asked to develop a method that reflects their unique character. The aim was to disseminate guiding values and instructions for actions to other contexts, so that other healthcare professionals and patients could learn to apply them to their situation.

Criteria for selection of the two programs included the level of experience (programs that functioned several years) and quality and robustness (identifiable programs grounded in the values of the movement). Furthermore, the programs had to be developed for different patient groups. The selection of the two programs was negotiated with key stakeholders of the movement, and resulted in the choice of a COPD program and Fibromyalgia program. In this article we focus on one program, the Dutch centre for COPD. This practice is appropriate as a case example for exploring the notion of self management from the perspective of shifting expectations and responsibilities.

The evaluation followed a responsive approach which implies that human beings are considered as active interpreters of their world and that those with a stake in the program (the stakeholders) are regarded as research partners [2]. The research project wanted to answer several questions. What made the evaluated programs so unique according to stakeholders (patients and professionals)? How could we describe the interaction between the patient and health professional and in what way did this interaction change from the past? Which working routines and underlying values characterized the programs? By answering these questions we aimed to develop transferable working routines grounded in a dialogical view of care and to describe what conditions would be necessary to implement such a working routine in different contexts (e.g. what competencies).

To evaluate the COPD program, we conducted in-depth interviews with relevant stakeholder groups; patients with COPD, medical doctors, nurses, therapists and managers. A criterion for selection of participants was variety: we wanted to gain as many as different experiences with the programs as possible. Furthermore, the participants were sampled according to their (professional of personal) involvement in the program. Everyone we approached was willing to cooperate; we had no negative responses. One time it was difficult to find the correct way of conducting a member-check to validate our analysis of interview data; the patient we interviewed 
had trouble talking on the phone because he was very short of breath, so we decided to make an extra appointment for a face-to-face meeting to talk about our interpretation of the interview.

In the COPD program interviews were held with two lung physiotherapists (four interviews in total), and a pulmonologist (interviewed twice). Furthermore interviews were conducted with two persons who suffer from COPD. All interviews were tape-recorded and entirely transcribed. We validated the interpretations of the interviews by doing individual member-checks and by following a hermeneuticaldialogical process [21]. This meant that the interpretations of earlier interviews were used as input during next interviews to develop ownership and a shared understanding of the program. When we started interviewing the style was open. Because our knowledge of the program grew as we talked to more respondents the interviews gradually became semi-structured; we learned about the issues that mattered and were better equipped to focus on certain topics.

The inductive analysis focused on recurring values, communication styles and relationships, and the data were related to theoretical insights from the field of ethics. The research team paid special attention to differences in opinion and perception between stakeholders; the aim was not to diminish differences, but to make them explicit and facilitate a dialogue. An example of the hermeneutic dialogical process was a series of conversations about taking medicine. Whereas the pulmonologist told that his patients did not experience difficulties in taking medicine, someone with COPD noted that the way the lung specialist explained the use of medication, could be improved. He found the physiotherapists more clear in this regard. In a subsequent conversation with the pulmonologist, we told him the persons' view, and discussed why this patient experienced shortcomings. Before introducing this experience of the patient at the pulmonologist, we asked the patient for permission. The patient agreed with us talking to the pulmonologist, because he already shared his opinion with the pulmonologist himself. By letting us talk to the pulmonologist again, his viewpoint could be introduced again, with the expectation that the pulmonologist would take action to improve his skills. A final step was a conversation between the medical specialist, respiratory therapists and the person with COPD to see what exactly could be improved.

The positive involvement of all the respondents of the program was striking. The research resulted in a mutual learning process. The health professionals and persons with COPD wrote lengthy remarks in response to our interpretations of the interviews and we had several talks about these interpretations. The actual research report included both programs and was published as a Dutch book [40].

\section{The Context: Dutch COPD Centre}

In 2003 a group of Dutch healthcare professionals and people with COPD discussed the need to improve the quality of the communication with each other. The purpose was to create more equal, dialogical relationships in which values as equality and self management played a prominent role. These professionals and people with COPD gained support from various larger organizations like the Royal Dutch 
Medical Association (KNMG), Dutch Patient and Consumer Federation (NPCF) and the Foundation for Nursing and Care-professionals (VV\&V). This was the beginning of a movement called Changing by Connecting (Verbindend Vernieuwen). This movement functions as an umbrella for several programs in which healthcare for the chronically ill is improved.

Chronic Obstructive Pulmonary Disease (COPD) is a disease of the lungs in which the airways have become constricted. It is a deficiency in ventilating. People who suffer from COPD have a short of breath and coughing is often a first sign of it. Diseases under the umbrella-term COPD are chronic bronchitis and emphysema. Although (one of) the primary cause(s) is tobacco smoke, according to the World Health Organization, COPD is not simply a 'smoker's cough', but an underdiagnosed, life-threatening lung disease. COPD is not reversible, but it can be managed, controlled and slowed down. Two percent of the Dutch population is diagnosed with COPD and 17 percent of the people above the age of 80 suffer from this chronic disease. Worldwide it is estimated that 210 million people suffer from COPD. This percentage is expected to rise because of pollution, unhealthy diets and physical inactivity (2).

People with COPD are short of breath. In the beginning mostly when being physically active, like cycling, running or doing hard physical labor. After a while, when the disease progresses, simple activities like walking the stairs, getting dressed and doing the dishes will also cause a shortness of breath. This shortness of breath results in increased fatigue and inactivity which have a negative effect on the patients' mental health also, thus creating a vicious circle. The common way to treat patients with COPD is to provide a mix of medication and physical therapy. COPD is a chronic disease and the development of this disease has to be seen within the historical context of chronic illnesses in general. In the past, it was very common for people with chronic illnesses to take rest and become less active. Nowadays, the effectiveness of rest is questioned and replaced by training and re-activation programs.

In the early 1980s in the Netherlands an alternative COPD program was developed by two lung physiotherapists and a pulmonologist who noticed that a growing amount of patients consulting them returned after a while with the same health concerns. The doctor advised rest, physical therapy and medication, but realized that for some patients, this was not sufficient. A centre for COPD was established. The centre offers a multidisciplinary group-program that consists of physical movement, exchanging experiences with other fellow patients in a group and education about physical and mental health by the use of insights from cognitive behavioral therapy.

The centre is embedded in a network of healthcare institutions, health insurance companies, regional professional associations and the patient association for COPD. Besides providing treatment, the network focuses on the development of guidelines and protocols for treatment. The quality of care is constantly monitored and improved through the exchange of experiences and knowledge. The participants of the network are patients, general practitioners, pulmonologists, (lung) physical therapists, families of the patients, pharmacists, nurses and psychologists. One of the characteristics of the network is its non-hierarchal structure. This means that the 
patient is really an equal 'partner in care', which is unique in the Dutch healthcare system. The participants of the network decided that in order to become an equal partner, being able to participate in a dialogue, the patient needs to be educated in a specific way. On an organizational level, the patient should learn how to participate in the network as a representative of a patient organization and on the individual level he should develop capacities to actively participate during the treatment. The patient needs to be trained, know what he could do when there are physical problems and complaints. In turn, the professionals need to understand and answer the questions of the patient and should be able to enter into a dialogue.

On a yearly basis, the COPD program consists of sixteen groups of eight patients, so in total about a hundred patients per year join the program, of which 75 percent or more suffers from severe COPD. The program is offered when the person with COPD consults the pulmonologist. The pulmonologist informs the patient about the program and together with the lung physiotherapist they decide whether to join the program or not. Most of the times, a referral to the program happens when the patient keeps having problems with accepting his disease, or is having problems with the amount of activities he can undertake during daily life.

The first step in the program is an interview with the lung physiotherapist. Preferably the partner of the patient joins this intake conversation. By using a special anamnesis form, the lung physiotherapist discusses the medical history of the patient, the way the patient and his partner experience the disease and the way it influences daily life. Since COPD is considered not to be just a lack of air, but rather a disability grounded in the life history and daily experiences of the patient the intake also focuses on the narrative of the patient (Who is the patient? What are important values in life?).

The next step is a test to determine how much strain a patient can endure. With the results, an individual training program is compiled. The actual training is carried out in a group of patients, where the lung physiotherapists supervise the exercises and ask lots of questions during the training. As indicated, the Dutch program tries to make patients more aware of their total state of being and way of living.

The activation is dosed; the term 'graded activity' is used, which means that the degree of activation starts at a low level, and is slowly progressing to more intensive levels. It is, however, the patient who decides which level is feasible. During the training the physiotherapists ask how the patient experiences the work out. Another underlying notion is that the physical activity needs not to be dependent on the level of pain or fatigue. Yet, it is very important that patients themselves discover how valuable the physical movement is for their total well-being.

The program teaches patients self-management. Patients have to learn to deal with their limitations and they learn this though physical exercise, but also by sharing experiences with a group of fellow patients.

The COPD program is successfully evaluated from a professional perspective in terms of a reduction of hospital admissions (15\% between October 2003-2004), admissions after three months (15\% same year), exacerbations (30\% ibid) and quality of life (10\% ibid) [30]. The patients evaluate the Dutch program also as successful. A patient: The program supports the activities I can do at home. Very simple exercises, walking, home trainer and household jobs, like washing the dishes. 
They state that overall doctors are less sensitive to the mental aspects of the disease, and have less ability to explain practical advices. They do notice, however, that the communication between the physiotherapists and the doctors is short: The lung physiotherapists have direct contact with the doctors. I do notice that the doctors don't talk a lot with each other, but they do talk with the therapists a lot, they seem to have a very easy accessible contact. The professionals of the program are very involved with the patients and know the balance between taking care and empowering patients. A patient: Here in the therapy they are much better at explaining (how to take my medicine). One patient even says that the program prolonged his life: They saved my life, because they taught me how to breathe. The patients also emphasize that the route that has to be walked to reach that result is difficult. One of the patients is very clear: I do not want to do it over again, all the physical training. It was a very, very tough year.

\section{Underlying Themes}

The evaluation gave insight in a variety of themes which helped answering the research questions as stated above.

\section{Patients' Life Story}

In the COPD program, the physiotherapist listens to the patients' life story and at the same time learns about and questions the values of the patient. The physiotherapist does that through introducing new insights and information about COPD. This often induces an increased understanding among the patient and partner about the way the disease influences their lives. The lung physiotherapist explains:

During the intake, when the atmosphere is right, patients realize they don't suffer from a shortage of breath only, but it's also 'I'm not feeling well in general'. When the patient thinks about that, talks and comes to the conclusion that he needs to work on that, than you are a step further in improving the quality of life.

Another example is the female patient who enters the centre remarking that following the program and the physical activities is impossible. After the intake with the physiotherapist she decides to stay; it was clear that the cause was her fatigue. That bothered her even more than her breathing problems. During the talk she cries and expresses she doesn't feel understood; 'working part-time and doing the household, it is too much for me'. Talking to the physiotherapist during the intake, she starts to understand the relation between smoking and her fatigue. She accepts the need to find a balance between her activities and quit smoking and decides to join the program.

From the start of the program it is important to understand the development of the patient's life; what he values, the important moments he experienced and how he coped with that. In the Dutch COPD centre, the telling of the illness narrative helps to shape and create experiences. Besides reflection, eliciting, articulating and 
questioning values, it also contributes to the direct experience of symptoms and suffering [24]. The telling of the life or illness story helps the therapist and patient to determine what specific treatment is needed and most of all: who the person is [3, 20]. A life story is a narrative of someone's life in order to give meaning to the things he experienced [31]. In the COPD program, the lung physiotherapist is trained in conversation techniques similar to those used in cognitive behavioral therapy to elicit and listen to the life story of the patient. In this context, 'listening' has to do with paying attention and showing a genuine involvement. The sincere 'presence' of the professional facilitates a natural conversation. It is not about accountability, fulfilling one's obligations; the professional adequately responds to the patient as a person. Listening has also to with summarizing and giving feedback.

\section{Integral View on Mind-Body Connection}

One purpose of the program is to increase patients' awareness of their own body and mind and their integration. Patients learn that it is not only shortness of breath they are bothered by, but also other aspects of their life like their awareness of their boundaries and the amount of physical activity they can handle during the day. The switch to this more integrated approach started in the early 1980s when the lung physiotherapists noticed that there is a very strong connection between someone's physical and mental or emotional state. A lung physiotherapist illustrates the problem:

Somebody doesn't want to get up anymore because he is short of breath. The other person (who tries to help) treats him very carefully, but that leads to inactivity. The condition diminishes because the patient is tight in the chest, becomes more tired, so he just wants to be left alone, he becomes afraid, his medical consumption increases and social desolation may follow.

Social desolation worsens the patients' situation. In the Dutch program it is important to stimulate the patient to stay socially active, continue to work and meet family and friends. The conventional way of treatment included rest, but the physiotherapists realized that had an opposite effect: rest leads to inactivity. The Dutch program illustrates that social functioning benefits the integral experience of the person with COPD. In order to strengthen the physical state and stay socially active, patients need to learn to think differently. Just realizing that inactivity increases health problems is not enough to change their behavior. Behavior that has been developed for years, changes step by step through training and increased awareness. Together with the physiotherapists and peers, patients reflect on their behavior and thought patterns. Often, this has to do with recurring themes, like the ability of patients to notice their limitations and accept when to take a rest:

The most difficult was to learn how to stop. Accept my boundaries. Since I was born, I am used stretching my boundaries (patient I).

After some exacerbations the hardest thing to do, was deceleration of the pace of my life and work, and to accept my limitations and this new, lower pace. When I cross my limit, my breathing increases and I'm snapping for breath. 
During the training the therapists helped me to regain my balance, but I lost other functions forever, unfortunately (patient II).

Whereas in the past physical issues were stressed one-sidedly, in the COPD centre observations of the emotional and mental state of the patient are of equal importance. This requires training in and openness towards mental and emotional areas. The physiotherapists of the Dutch COPD-program joined a short training in cognitive therapy in order to learn how to approach patients.

Decartes defined body and mind in terms of mutual exlusivity. The body is pure res extensa-unconscious, material-whilst the mind is res cogitans-mental, without location, bodyless [11]. Descartes described that the mind could 'control' the body, but mind and body would be two distinct substances. This Cartesian dualism with the mind with its consciousness and self-awareness and the brain with its intelligence is confirmed by studies by neuroscientists. This material monist view reduces mental phenomena to brain processes [12, 22, 28, 39]. It does not need explanation that this dualism influenced medical science and its focus. We can see developments however, that illustrate that the acceptance of a non-material, nondualistic relation between mind and body grows. This is especially the case among some psychologists and psychotherapists. In the other program we evaluated, the treatment of people with fibromyalgia, professionals used insights from Mindfullness Based Cognitive Therapy (MBCT). MBCT is proved to be an effective treatment for several personality disorders [19]. Research about the effectiveness of cognitive therapy for people with physical chronic illnesses is still in its infancy (e.g. $[5,41]$ ) but the assumptions about the mind-body connection already percolate in these kinds of multidisciplinary programs.

More philosophically, these assumptions deal with an integral philosophical approach to the mind-body problem. In general, this has been one that acknowledges the essential unity of body and mind while emphasizing consciousness, or interior subjective awareness, as primary. Indirectly, one refers to this unity when stating: 'I am a body versus I have a body' [1, 34, 35]. This relates to the work of Merleau-Ponty. According to Merleau-Ponty [27] the human body is not just a domicile of the mind but, the 'higher' functions, including thought itself, should be regarded as bodily functions referring to the whole body in its relational being-inthe-world. We could find this relational view in the case example where both patients and therapists need to take an appropriate view of the relation between mind, body and its 'being in the world' in order to enable effective dialogue and therapy.

\section{Self-Management}

Taking care of one's boundaries is closely related to the concept of self management. Patients have to learn to deal with their limitations. If they experience difficulties, they need to know where to get help and how to ask for it. They need to change the belief and thought that 'asking' is 'not a sign of weakness, but of strength' (physiotherapist). Self management also means: setting limits and 
knowing what decisions to make in one's own interest. The pulmonologist gives an example:

A patient consulted me when he was unable to cycle with his friends. I examined him, explained the cause of his problems and prescribed medicine. After a while, this patient consulted me again and said: 'But doctor, I am still unable to cycle with my friends!' I could have answered something like 'then you have to find another group of friends or ask them to slow down'. Instead, I told him: 'We can also find another way to solve this. Let's look if physiotherapy has an effect. Let's see if we can find out what your limits are.' His physical condition was fine, but he had to learn how to set limits (pulmonologist).

Self management includes the ability to make adequate decisions. Several factors influence the ability to make the right decisions, like the existence of comorbidity. People with COPD have an increased risk to get other health problems, like a lung infection [23]. Fear for drawbacks and additional problems may prevent people to become active. Therefore, an important part of the program consists of education. One example is a card for patient with an SOSplan created by the health professionals in cooperation with the patients. The card carries advices that match the symptoms and feelings of the patient at a specific moment. Patients can consult the card in case of problems and decide what to do.

\section{Learning from Fellow Patients}

Still another example of how self management is implemented is the interaction in the larger group. Patients need this support of a group of fellow patients. It helps them to learn to accept their disabilities, because of the increased awareness through listening to each other's stories. The lung physiotherapist:

We talk about our observations during the training and we ask whether other patients recognize them. Sometimes there are tears, but that is possible because the people trust each other. People recognize the other persons' story. They all feel the same. And then you see that they support each other. Help is offered by fellow patients.

Patients recognize each other's stories and find them comforting in an empowering way: they hear different perspectives on the meaning of the disease, and may discover that their own understanding is quite limited. The sharing of experiences also happens during informal meetings, like a coffee break. A patient:

During the coffee-break we talk and exchange ideas and that's how we learn from each other. You're among colleagues, there is also a lot of laughter, besides sadness, we're also having fun a lot of the time!

While joining the group, patients learn practical methods from peers to cope with COPD. And they come to see their situation in a new light by humor and fun. 


\section{Professional Competences}

To be able to work with and in groups like this, professionals need specific competences, from both a professional and a personal point of view. The approach of the therapists in the group-work varies from keeping a professional distance to openly expressing emotional involvement; they facilitate the dialogue by sharing their observations of the training and their own, more personal experiences. In that way they induce a conversation about specific subjects and create an atmosphere of trust. The professional needs to be able to think and act beyond the limits of their discipline and workplace. An example is the lung physiotherapist who works in the hospital, but often visits patients when they are unable to attend the training because of a relapse. The therapist advices on what the patient can do at home, to help the patient to become active again and resume the training. Another skill a professional needs is the ability to act in an independent way. Where new, innovative programs are developed, they will meet resistance of more conventionally oriented professionals. For example, during the development of the Dutch COPD centre, other professionals doubted the design of the program and especially the duration of it. The lung physiotherapist:

We experienced a lot of resistance. They thought a patient cannot be a manager of his own disease. We were convinced, at the time, that patients were equipped enough to continue on their own (to leave the program) after six to 8 weeks, whilst scientific research stated that a minimum of three to 6 months was required to treat the patient.

Another competence that is mentioned is empathy. The pulmonologist tells:

Empathy. To be in sympathy with. If you do not have empathy, the conversation with the patient will be very rational. You will be able to help someone, but only till a certain degree. You must be able to talk about emotions and experiences.

\section{Narrative, Dialogical and Relational Work}

In the Dutch COPD centre the COPD patient is no longer a passive recipient of medical treatment delivered by a medical specialist. He becomes a partner in the program, and takes on responsibility for his health. This new division of responsibilities is, however, not something that comes about automatically, or can be planned and organized by clinical guidelines and protocols. The ethicist Margaret Walker [42] explains that from an ethical (versus juridical) perspective responsibilities are actively negotiated among people by exchanging normative expectations. In their interactions people develop shared understandings over what they expect of themselves and others, and vice versa. This entails moral issues like the interdependences between people and the risks of a certain division of responsibilities. When people begin redefining responsibilities they redefine themselves, 
their roles and their relationships. This requires a lot of narrative, dialogical and relational work.

First of all the doctor needs to redefine his traditional medical expert role. In the paternalistic patient-doctor relationship the medical specialist is unlikely to have much interest in discussing patients' concerns [18, 29]. The professional decides, acting in the best interest of the patient without having to explore the patients' values and concerns. The professional acts as the guardian of the patient. This paternalistic relationship is perhaps appropriate in situations where there is a life threatening or an acute illness; in the case of chronic COPD, it is highly unlikely to work. So, the medical specialist needs to develop a new role towards the patient. In the COPD centre, the pulmonologist shifted his role to that of a teacher, educating the patient to recognize his limits and to find new ways of dealing with the disease. Likewise patients had to become more active in both defining their problems and in determining the appropriate treatment. One of the hardest things for a person with COPD is that he and others initially see him as a patient. This is the effect of COPD being a chronic disease; having an illness still means, for most of us, going to bed, taking medicine, to stop and quit doing what we used to do. We still associate an illness, even if it is chronic, with an acute disease. So, one of the biggest challenges is to redefine COPD patients as persons with COPD. Once the person with COPD begins to define himself as such, he is able to see that he is not the disease, that he is able to carry on his life despite limitations and that he can take on responsibilities for the quality of his life. This is not a one way process; both parties (patients and professionals) have to develop a new understanding of their own and the other's role.

Secondly, both parties in the COPD program need to redefine their relationship. The clinical distance common for the paternalistic relationships is no longer suitable. In the COPD program the patient and professionals developed an engaged and empathic relation. In each instance a lot of energy was invested, mainly by the physiotherapists, in helping to understand the patient and the story of the patient. The story is seen as a way of making sense and giving meaning to experiences. The lung physiotherapists attended a specific course to learn how to question patients. The story is not only about the physical disease, but also about the emotional and social impact of it. Think of the female patient who was initially not at all motivated to join the program. The therapists had to elicit the story and listen to it, and then had to interpret what was going on in the life of this woman. Why did not she want to quit smoking at first, why was she so stubborn? The therapists began to develop a sense of what was going on, not by asking what she needed or wanted, but by focusing on her personal life-story. They discovered that the fatigue was more urgent than the breathing problems. The fatigue had to do with her problems combining a job and doing the household and the high expectations of herself. Furthermore, her husband seemed quite insensitive to her problems. By telling her story to the therapists and by reflecting on it together, the woman was able to give meaning to her experiences. The therapists had to interpret what she valued in life and which treatment could help her. In this case, the therapists acted as counselors or advisors assisting the patient to elucidate and articulate her values. It became less important for her to meet everyone's needs and more important to treat her own 
mind and body in a healthy way. That's why she decided to join the program. Another example is the patient who needed the conversations from the physiotherapists to help him to accept a new balance in his life. He could not do this on his own, but needed the dialogue with the professionals to discover what was right in his life at that moment in time.

This corresponds with the purpose of the COPD program as mentioned: to develop a new lifestyle in a dialogic way through the introduction of self management. The relationship between the professional and the patient is a means to reach that goal.

We see here that the traditional, one way of communication is replaced by a more dialogical conversation in which the patient as well as the partner and the professional are engaged [18]. Whereas in the past healthcare professionals gave primacy to the cure of the physical disease, in the COPD centre, the emphasis is on the meaning of the disease and finding a way to deal with the disease by the patient himself. Therefore, empathy and listening are important skills that need to be developed among professionals. Our findings illustrate that one of the patients experienced the conversation with the pulmonologist as a 'one-way' conversation. Unlike his relation with the physiotherapists, he felt less understood by the pulmonologist. Hence, concerning 'empathy', the professional needs to be trained to show a genuine involvement with the patient, without losing himself. During listening, three things are important: hearing, understanding and exchanging [10]. 'Hearing' implies that the professional is able to rephrase what the patient is telling him. Understanding is about the ability to hear the meaning in the words and exchanging deals with an advice, remark or observation that arose while hearing and understanding. These are three aspects of listening that are important in forming relationships with patients in the COPD centre.

Communication does not only take place between professionals and patients, but also among fellow patients. The safety of a group is an important component to assist patients in their empowerment. The group helps them to recognize that they are not alone with their problems; they need not to be ashamed of themselves. Furthermore, the stories exchanged and responses are often more universal. The group sessions stimulate participants to socialize, to make contact and to stimulate and support each other. Together the patients can write their we-story; the story of how they gained back control over their lives.

Finally, the new division of responsibilities entails relational and communicative work among professionals. The multidisciplinary focus of the program requires personal skills from all the professionals. Old values like hierarchy and control are replaced by values as equality and autonomy. Old structures between doctor, nurse, therapist and also organizational structures (like first en second echelons) vanish and are replaced by a network organization with a dialogical way of communication. Direct and easy accessible communication between professionals, including new participants like lung physiotherapists, psychologists, general practitioners and welfare workers, requires constant attention. Different vantage points should be respected and if necessary, negotiated. To overcome feelings of insecurity and resistance courage, entrepreneurship and enthusiasm are needed. Also between 
professionals, the importance of listening and building an atmosphere of trust is important.

\section{Conclusions}

The case example illuminates that people with COPD (1) need the surrounding of a larger group of fellows to learn to accept their disabilities. Awareness that COPD is more than just a lack of air is just a start. According to people with COPD it is a first step towards a better quality of life while health care professionals regard it as a first step to investigate other problems in life and to break through the circle of inactivity. In a reflection on the case we argued that a chronically ill person is not just a consumer; he is also a conversation partner, learning from as well as teaching his professionals and fellow patients. Likewise the healthcare professional is more than just an information provider; he is often also a coach and Socratic guide who challenges life styles taken for granted, who motivates patients to change their behavior and who gives support and practical feedback. Doctors as well as patients have to grow into these new roles and establish new relationships. Empathy, support, listening to the patient's story and dialogical interaction are as important as giving information and asking for consent.

Self management is often regarded as a panacea for patients with a chronic disease. Patients have to actively deal with their situation in order to regain autonomy. Self management is at the same time highly contested. Critics state that the patient has to take up a role which he does not want to play, and often is not able to, and that professionals leave patients alone in their suffering. Although these views of self management are opposed, they share the presupposition that self management is equal to being independent and in control. In this article, we have shown that the practice of self management in a Dutch COPD centre does not focus on independency and control. It rather involves a new division of responsibilities, in which patients and professionals develop new roles and relationships. Patients and professionals have to become partners in care. This implies a lot of relational, narrative and communicative work. Both parties have to grow into the new roles, in which values like equality, autonomy, and genuine involvement are important. The professional needs to develop skills like empathy, giving support and listening. The patient needs to develop an awareness of limits, learn how to share experiences with fellow patients in a group and how to use self management to change his life style for the better. An underlying assumption is that mind and body are connected in a subtle way and that patients can only improve their quality of life when they work on both aspects. Another assumption is that patients function in a social system and that in order to learn how to cope with their disease, they should play with their position in the system and the limits they meet. Patients of the COPD centre have learned how to do that and have also learned that it is a fragile process that never stops; self management needs continuous attention and relational support. 


\section{Notes}

(1) In scientific discourse, the term 'participant' is widely used to describe the subject. In this article we wittingly use the terms 'patient' and 'person with COPD'. People with COPD prefer the last term because they regard the disease as something they have. They are not the disease itself. In the context of the case of the COPD centre, we decided to talk about 'person or people with COPD'. In the more analytical paragraphs, we use the term patient.

(2) This is based on information provided by the website of the World Health Organization http://www.who.int/mediacentre/factsheets/fs315/en/index.html

\section{References}

1. Abma, T. A. (2002). Hidden images of self: A relational-constructionist approach to identity. In C. Ryan \& T. A. Schwandt (Eds.), Exploring evaluator role and identity. Information Age Publishing.

2. Abma, T. A., \& Widdershoven, G. A. M. (2005). Sharing stories: Narrative and dialogue in responsive nursing evaluation. Evaluation \& The Health Professions, 28(1), 90-109.

3. Abma, T. A., Oeseburg, B., Goldsteen, M., Widdershoven, G. A. M., \& Verkerk, M. (2005). Two women with multiple sclerosis. Conflicting normative expectations between patients and their caregivers. Nursing Ethics, 12(5), 479-492.

4. Abma, T. A., Widdershoven, G. A. M. Oeseburg, B., \& Verkerk, M. (2009). The quality of caring relationships. Journal of Behavioural Management (Dove Medical Press, accepted for publication).

5. Al-Obaidi, S. M., Nelson, R. M., Al-Awadhi, S., \& Al-Shuwaie, N. (2000). The role of anticipation and fear of pain in the persistence of avoidance behavior in patients with chronic low back pain. Spine, 25, 1126-1131.

6. Badcott, D. (2005). The expert patient: Valid recognition or false hope? Medicine, Health Care and Philosophy, 8(2), 173-178.

7. Barry, C. A., Bradley, C. P., Britten, N., Stevenson, F. A., \& Barber, N. (2000). Patients' unvoiced agendas in general practice consultations: Qualitative study. BMJ, 320(7244), 1246-1250.

8. Beauchamp, T. L., \& Childress, J. F. (1994). Principles of biomedical ethics (4th ed.). New York/ Oxford: Oxford University Press.

9. Bissell, P., May, C. R., \& Noyce, P. R. (2004). From compliance to concordance: Barriers to accomplishing a re-framed model of healthcare interactions. Social Science and Medicine, 58(4), $851-862$.

10. Bolsenbroek, A. (2007). Het helpende gesprek; de methode van Denijs Bru. Humanistiek, 32, 24.

11. Bordo, S. (1999). Feminist interpretations of Rene Descartes. Pennsylvania: Pennsylvania State University Press.

12. Boscarino, J. A., \& Chang, J. (1999). Electrocardiogram abnormalities among men with stress-related psychiatric disorders: Implications for coronary heart disease and clinical research. Annals of Behavioral Medicine, 21, 227-234.

13. Britten, N., Stevenson, F. A., Barry, C. A., Barber, N., \& Bradley, C. P. (2000). Misunderstandings in prescribing decisions in general practice: Qualitative study. BMJ, 320(7233), 484-488.

14. Britten, N., Stevenson, F. A., Barry, C. A., Barber, N., \& Bradley, C. P. (2000). Misunderstandings in prescribing decisions in general practice: Qualitative study. BMJ, 321(7269), 1160-1161.

15. Cox, K., Stevenson, F., Britten, N., \& Dundar, Y. (2003). A systematic review of communication between patients and healthcare professionals about medicine taking and prescribing. London: GKT Concordance Unit, King's College.

16. Department of Health. (2001). The expert patient: A new approach to chronic disease management in the 21st century. London: Stationery Office.

17. Dutch Ministry of Health, Welfare and Sport. (2001). Met zorg kiezen (in Dutch). Den Haag: Dutch Ministry of Health, Welfare and Sport (Ministerie van Volksgezondheid, Welzijn en Sport). 
18. Emanuel, E. J., \& Emanuel, L. L. (1992). Four models of the physician-patient relationship. JAMA, 267, 2221-2226.

19. Evan, S., Ferrando, S., Findler, M., Stowell, C., Smart, C., \& Haglin, D. (2008). Mindfullness based cognitive therapy for generalized anxiety disorder. Journal of Anxiety disorder, 22(4), 716-721.

20. Goldsteen, M., Abma, T. A., Oeseburg, B., Verkerk, M., \& Widdershoven, G. A. M. (2007). What it is to be a daughter? Identities under pressure in dementia care. Bioethics, 21(1), 1-12.

21. Guba, E., \& Lincoln, Y. (1989). Fourth generation evaluation. Newbury Park, CA: Sage Publications.

22. Gupta, M. A. (2006). Somatization disorders in dermatology. International Review of Psychiatry, 18, 41-47.

23. Heijmans, M. J. W. M., Spreeuwenberg, P., \& Rijken, P. M. (2005). Monitor Zorg-en Leefsituatie van mensen met astma en mensen met COPD, Trends en ontwikkelingen over de periode 2001-2004. Utrecht: Nivel.

24. Kleinman, A. (1988). The illness narratives: Suffering, healing and the human condition. New York: Basic Books.

25. May, C., Allison, G., Chapple, A., Chew-Graham, C., Dixon, C., Gask, L., et al. (2004). Framing the doctor-patient relationship in chronic illness: A comparative study of general practitioners' accounts patients want to treat as a whole person and were also important. Sociology Health and Illness, 26(2), $135-158$.

26. McKinley, R. K., \& Middleton, J. F. (1999). What do patients want from doctors? British Journal of General Practice, 49(447), 796-800.

27. Merleau-Ponty, M. (1968). The visible and the invisible, followed by working notes. In C. Lefort (Ed.). Evanston: Northwestern University Press.

28. North, C. S. (2002). Somatization in survivors of catastrophic trauma: A methodological review. Environmental Health Perspectives, 110, 637-640.

29. Oeseburg, B., \& Abma, T. A. (2006). Care as a mutual endeavour. Medicine, Health Care and Philosophy, 9, 349-357.

30. Peters, A., Gorter de Vries, L., van Slobbe, A., \& Peters, N. H. (2005). Doorbraakproject Ketenkwaliteit COPD van CBO leidt tot minder ziekenhuisopnames, afname van zorgvraag en toename kwaliteit van leven door verbetering zelfmanagement COPD-patiënt. Pulmoscript, 16, 2.

31. Ricoeur, P. (1983). Temps et récit. Editions de Seuil, Paris.

32. Rycroft-Malone, J., Latter, S., Yerrell, P., \& Shaw, D. (2001). Consumerism in healthcare: The case of medication education. Nursing Management, 9(4), 221-230.

33. Say, R., \& Thompson, R. (2003). The importance of patient preferences in treatment decisionschallenges for doctors. British Medical Journal, 327(7414), 542-545.

34. Slatman, J. (2009). Transparent bodies: Revealing the myth of interiority. In R. van de Vall \& R. Zwijnenberg (Eds.), The body within: Art, medicine and visualization (pp. 107-122). Leiden: Brill.

35. Slatman, J. (2009). Beelden van het Lichaam; van verleden tot heden. Schrift 245 Lichaam in Beeld, 41(5), 147-152.

36. The Council for Public Health and Healthcare. (2003). Van patiënt tot klant. Zoetermeer: The Council for Public Health and Healthcare.

37. Thorne, S., \& Paterson, B. (1998). Shifting images of chronic illness. Image Journal of Nursing Scholarship, 30(2), 173-178.

38. Tyreman, S. (2005). An expert in what?: The need to clarify meaning and expectations in "The Expert Patient". Medicine, Health Care and Philosophy, 8, 153-157.

39. van der Kolk, B. A., Pelcovitz, D., Roth, S., et al. (1996). Dissociation, somatization and affect dysregulation: The complexity of adaptation to trauma. American Journal of Psychiatry, 153, 83-93.

40. Visse, M., \& Abma, T. A. (2008). Dialooggestuurde zorg(innovaties): Vernieuwende zorgpraktijken, verbindende waarden. Den Haag: Lemma.

41. Vlaeyen, J. W. S., Peters, M. L., Roelofs, J., Jong, J. R., de Sieben, J., Houben, R., et al. (2002). Serie onderzoek en psychotherapie: Catastrofale misinterpretaties. Vrees voor beweging, letsel en pijn bij lage-rugpijn. Tijdschrift voor Psychotherapie, 28, 205-222.

42. Walker, M. U. (1998). Moral understandings: A feminist study in ethics. New York/London: Routledge.

43. Widdershoven, G. A. M., \& Abma, T. A. (2007). Hermeneutic ethics between practice and theory. In R. E. Ashcroft, A. Dawson, H. Draper, \& J. R. McMillan (Eds.), Principles of health care ethics (pp. 215-222). West Sussex: Wiley. 